\title{
Transferring Portfolio Selection Theory to Customer Portfolio Management - The Case of an e-Tailer
}

\author{
by
}

Dennis Kundisch, Stefan Sackmann ${ }^{1}$, Markus Ruch ${ }^{1}$

February 2007

in: D. Veit, D. Kundisch, T. Weitzel, C. Weinhardt, F. A. Rabhi, F. Rajola, Hrsg., Proceedings of the 3rd International Workshop on Enterprise Applications and Services in the Finance Industry, Montreal, (Kanada), Dezember 2007, Springer, Heidelberg, 2008.

\footnotetext{
1 Albert-Ludwigs-Universität Freiburg, Institut für Informatik und Gesellschaft, Abteilung Telematik
} 


\title{
Transferring Portfolio Selection Theory to Customer Portfolio Management - The Case of an e-Tailer
}

\author{
Dennis Kundisch ${ }^{1}$, Stefan Sackmann², Markus Ruch² \\ ${ }^{1}$ University of Freiburg, Germany \\ Institute of Economic Research, Department of Information Systems \\ Platz der Alten Synagoge, 79085 Freiburg, Germany \\ dennis.kundisch@vwl.uni-freiburg.de \\ ${ }^{2}$ University of Freiburg, Germany \\ Institute of Computer Science and Social Studies, Department of Telematics \\ Friedrichstr. 50, 79098 Freiburg, Germany \\ \{sackmann|ruch\}@iig.uni-freiburg.de
}

\begin{abstract}
Investing in existing customers is widely accepted as a promising strategy because it is believed to be less costly than attracting new ones. Recent research by Reinartz et al. [39] provides indications, however, that it could also be profitable to simultaneously focus on a customer segment being more transaction-oriented. In this contribution - using the example of an e-tailer - we specifically look at the question regarding the optimal mix of different customer segments within a customer portfolio. Portfolio Selection Theory is applied to develop a model to determine the optimal proportion of the different customer types from a value-based risk management perspective. A first evaluation is realized with a publicly accessible set of empirical data from the e-tailer CDNow. The results of the model provide a basis for the alignment of future CRM-activities.
\end{abstract}

Keywords: Customer Portfolio Management, Risk Management, E-Commerce, Portfolio Selection Theory, eCRM, integrated Risk-Return Management

\section{Introduction}

In competitive economies, the main goal of every company is to maximize shareholder value [30]. Many authors, e.g. [20], [23], [35] argue that the basis of a company's profitability is its customers. Hence, an increase in shareholder value firstly requires an increase in customer value and a building of strong customer relationships as a means of gaining competitive advantage as proposed, e.g., by [40]. This insight has led to some fundamental changes in marketing theory as well as in practice towards a customer-centric view and the emergence of Customer Relationship Management (CRM). CRM centers on the valuation, selection, acquisition, retention, and development of durable customer relationships with the objective of allocating limited resources in order to maximize the value of a company. 
The empirical findings regarding acquisition and retention strategies are mixed. A rule of thumb in marketing says that maintaining an existing customer relationship is far less expensive than acquiring a new one [2]. There are quite a number of contributions that suggest focusing on existing customers, assuming a positive lifetime-profitability relationship [33], [36], [37], [49]. However, Dowling et al. [12] question such a lifetime-profitability relationship by analyzing customer loyalty programs and have suggested a different examination. Garbarino et al. [17] as well as Ganesan [16] have shown that a differentiated treatment of transaction-oriented (short-term) and relationship-oriented (long-term) customers with appropriate marketing tools is advisable. Reinartz et al. [38] find strong evidence that transactionoriented customers may be a very profitable segment, which should not be excluded from strategic considerations. Still the question remains about the optimal mix of these segments within a customer portfolio.

In this contribution, we suggest a model that helps in determining the optimal configuration of a customer portfolio of transaction- and relationship-oriented customers. The model is based on Portfolio Selection Theory according to [31] and particularly exploitable for e-tailers due to the potentials of the Internet for adequate relationship management [48]. Basically, the Internet as a communication channel enables e-tailers to vary the interaction according to the preferences of their customers. Results of a current online survey among German corporations indicate that most companies $(76 \%)$ already rely on CRM software to support their CRM activities - and another 9\% plan to do so by the end of 2008 [44]. However, the use of CRM software for controlling the overall customer portfolio according to superordinated quantitative goals like, e.g., risk management has been devoted little attention so far.

The paper is organized as follows. The next section provides an overview of recent research in customer relationship management with respect to quantitative customer portfolio management. Subsequently, we present our customer portfolio model and apply it to a publicly accessible data set of the online retailer CDNow. After a brief discussion, the basic, static model is expanded to get a dynamic view. Finally, the results of the paper are summarized and directions of further research are discussed.

\section{Customer Relationship Management and Portfolio Theory}

One basic condition for efficiently managing customer relations is the ability to estimate a customer's value for a company. A customer valuation concept, compatible with the principle of shareholder value that has gained broad attention in marketing literature and CRM research, is the Customer Lifetime Value (CLV). However, whereas marketing literature discusses the concept of CLV in detail, it still lacks practicability, since the estimation of future profitability is uncertain [50]. Thus, in a non-contractual relationship between a company and customers, which is particularly true of e-tailers selling, e.g., books or CDs on the Internet, the assumption of a deterministic world, where future cash flows are known with certainty, seems to be fairly unrealistic [28]. The consideration of risk, i.e. the deviation of cash flows from their expected value, is therefore crucial for a risk-averse decision maker. 
Traditional customer valuation concepts concentrate on assessing individual customers [24]. However, it is not enough to evaluate customers one by one and consequently decide on acquisition and retention strategies. Not just the risk within a single customer relation, but the risk contribution of each customer to the customer portfolio should be taken into account in a customer portfolio valuation. For reasons of simplification and the ability to better predict individual customer behavior, as well as strategic target group considerations, customers are often grouped into segments. These segments should be formed by trying to group together customers exhibiting similar buying behavior [51]. E.g. students that always buy a lot of books at the beginning of each term could form one segment,. Consequently, these segments can be addressed by specific marketing campaigns. Based on an appropriate segmentation, portfolio effects in terms of risk diversification - just like in a portfolio of financial assets - can be assumed and should be taken into account [11]. Interestingly, there are only a few contributions on this issue.

Incorporating risk and at the same time a portfolio view into customer valuation, some authors propose the usage of the weighted average cost of capital (WACC) of a company - based on the capital asset pricing model (CAPM) - as minimum rate of return [11], [20], [30], [25], [23], [28], [41], [42]. It is argued that the security market line may be used to adjust the specific WACC of any risky investment alternative and thus the beta value of a customer (segment) reflects the systematic business risk of the segment and the systematic financial risk of the company itself [30]. Consequently, the net present value (NPV) of the customer segment is given by the expected cash flows, discounted with the segment-specific risk-adjusted WACC. However, CAPM just takes systematic risks into account, whereas it is assumed that unsystematic risk can be neglected due to perfect diversification. Moreover, defining a market portfolio with respect to customers is quite a challenging task. Ryals [42] as well as Dhar et al. [11] define the "market portfolio" in the CRM context as the company's current customer base. In our view, this is not adequate if the company is following a growth strategy. This will most likely result in changing segments weights and the overall structure or the customer portfolio over time. Another shortcoming of the CAPM is the assumption of homogeneous expectations of all investors. This assumption is crucial for the existence of the market portfolio and the equilibrium on capital markets [8].

To take the risk of future cash flows as well as the customer portfolio into account, other authors, e.g. [3], suggest applying Portfolio Selection Theory according to [31]. The transformation of financial theory to other disciplines is not new though. Cardozo et al. [5], in comparison, suggest applying Markowitz's theory in product portfolio decisions. Although applying Markowitz's theory in a non-financial context also brings some shortcomings - which have led to an interesting discussion, see [6], [9] -, it nevertheless seems well-suited for providing reasons for customer portfolio decisions for the problem in question. This is discussed and argued in further detail in the next section. 


\section{A Model for Analyzing Customer Portfolios from an Integrated Risk-Return Perspective}

"Customers as Assets" is the title of an often cited contribution by Gupta and Lehmann [19] - and this is exactly the viewpoint that is taken in the approach proposed below. Furthermore, it has been widely acknowledged in literature (e.g. [23], [43]) that customer relationships indeed share characteristics with other business assets: They generate a risky cash flow. Thus, just like financial assets, they provide for an expected return, measured, e.g., as a CLV. Some of them provide a larger CLV but their cash flows may be unsteady and therefore more risky, whereas the CLV of others may be smaller but more stable [159. However, there are also some major differences between customers and financial assets. This limits the transferability of Portfolio Selection Theory to customer relationships and is therefore discussed in the following section.

\subsection{Transferability of Portfolio Selection Theory to customer relationships}

The basic condition that an investment generates some kind of return which is uncertain is fulfilled for financial assets as well as for customers considered as assets. Besides this, there are a number of assumptions that come with the application of Portfolio Selection Theory [31] and have to be taken into consideration:

- Investor's decision: Risk-averse investors seek to maximize expected utility. They regard investment alternatives as being presented by a probability distribution of expected returns over some holding period. Decisions are solely based on return and risk, thus their utility curves are a function of expected return and the expected variance of returns only. There seems to be no substantial difference between financial assets and customers as assets with respect to the decision rational. For a given level of risk, investors prefer higher returns to lower returns and vice versa for a given level of expected return, investors prefer less risk to more risk. In order to make rational decisions according to the Bernoulli principle, one either has to assume a quadratic utility function - which will be rarely the case in reality - or assume normally distributed returns. The authors are not aware of any study that deals with typical distributions of CLVs within specific customer segments. This appears to be an open issue for further research. ${ }^{1}$

- Given and stationary values for return, variances and co-variances: The parameters that go into the optimization model are assumed to be given and stationary. Since objective probabilities are in general not known, "probability beliefs" or socalled subjective probability distributions are used [32]. At this point, there is again no major difference between financial assets and customers as assets. One might argue that there is much more information available on financial assets compared to customers and customer behavior. However, with powerful data warehouses being in place, customer behavior is no longer a "black box" and it is an open research

1 However to assume a normal distribution seems not only to be common in financial markets but also with respect to customer buying behavior, see e.g. [46]. 
question as to whether the estimated values for financial assets are far more accurate compared to the estimations that have to be made for customers. Equally, the assumption about stationary values is a limitation that hits the applicability of the model in both cases. A company unexpectedly selling off large parts of its business will alter the risk-return characteristics of its stock, just as a customer experiencing a change in his circumstances, e.g. through marriage, hence changing his buying behavior, which in turn influences his CLV. As long as the chosen time horizon for the application for the model is not too long, such unexpected changes should be not too severe.

- One-period optimization: The basic model of Markowitz just considers a one-time optimization. The weights of the assets are determined at the beginning so as to maximize expected utility at the end of the period. The use of CLV as measure for return does not offend this assumption.

- Complete and frictionless market: In financial theory it is assumed that the market is without frictions, i.e. no taxes, no transaction costs and arbitrary divisibility of assets. Obviously, distortions can be found in financial markets as well as in the market of customers. Taxes diminish the expected CLV of each customer by affecting the underlying profit margin. Based on a tax system with constant tax rates on profits, taxes can be easily incorporated in the model. ${ }^{2}$

However, with respect to transaction costs, there are clear differences between financial assets and customers as assets because there is no liquid market for customers. Although transaction costs can be lowered by new means of electronic communication and a high level of automation, acquiring and also "selling", i.e. getting rid off ${ }^{3}$, of customers is still affiliated to transaction costs that may vary heavily according to the current market circumstances. This quality generally limits the applicability of portfolio theory in this context. Thus, we do not claim to apply our model with the objective of adapting the current customer portfolio according to the model results right away. The aim, in fact, is to obtain valuable information about the status quo of the current portfolio and to give an idea of where a theoretical optimum would lie. Thus, the information provided by the model shall be complementary to the use of other decision tools for strategic management and, in a first step, transaction costs are not of eminent importance here. ${ }^{4}$

The last issue, the divisibility of assets may be a problem for companies in markets with just a few customers, like component suppliers for the automotive industry. ${ }^{5}$ However, when talking about e-tailers like Amazon that globally addresses millions of private clients one may attest an approximate arbitrary divisibility.

2 However, since different companies, e.g. based in countries with different tax schemes, generally face different tax rates, there should be opportunities for tax arbitrage which will have an effect on market prices.

3 This issue is known as "selective demarketing" according to Kotler et al. [27]. In the context with CLV, it has recently gained increasing importance in literature, see e.g. [52].

${ }^{4}$ In a further evolution of the model proposed below, transaction costs should of course be incorporated just as in financial theory, much like in, e.g., [18] - to name just one out of numerous contributions on the issue of portfolio theory with transaction costs.

5 Here, contributions such as [4] about key account management and respective portfolio models, from a strategic management point of view - may be more useful. 
In practice, a company needs both: An optimization of the customer portfolio [43] and, at the same time, an efficient management of individual customer relationships [38]. Ideally, these two issues should be simultaneously optimized. Due to the complexity of this optimization, it seems appropriate to split this process up into two steps: Firstly, a company decides on the overall customer portfolio. Here, just broad customer segments are considered. Secondly, the customer relationships within the (optimal) customer portfolio are managed as an individual basis as possible. Since a lot has already been written on the second step, we concentrate on the analysis of customer portfolios from an integrated risk-return perspective. This focus is also advisable because the application of Portfolio Selection Theory to customers as assets is, as discussed above, more suitable to the identification of the optimal overall customer portfolio. We start with a simple segmentation approach just distinguishing loyal, i.e. relationship-oriented customers and transaction-oriented customers, i.e. customers that do not feel committed to a company after buying some products there. The transfer and application of Portfolio Selection Theory requires a few (additional) assumptions about the customers and the characteristics of a customer relationship. ${ }^{6}$

\subsection{Model Assumptions}

\section{(AC) Customers}

Relationship-oriented customers are customers that repeatedly buy after a successful acquisition in $t=0$ at two or more points in time $t \in\{0, \ldots, T\}$. Transaction-oriented customers are customers that buy just after a successful acquisition in $t=0$ and subsequently stop buying from this e-tailer. ${ }^{7}$

(ACS) Customer Segments

There are two ex ante observable and disjunctive customer segments $i \in\{R ; S\}$ in the market: Segment $R$ comprises all relationship-oriented customers and segment $S$ comprises all transaction-oriented customers. A segment $i$ yields the cash inflow $C F_{i, t}^{\text {in }}$ which is the average periodic revenue per capita at time $t$, with $t \in\{0, \ldots, T\}$, as well as the average cash outflow per capita $C F_{i, t}{ }^{\text {out }}$ that consists of direct costs, i.e. costs for acquisition, service and advisory as well as transaction costs. The segments are stable over the planning horizon, i.e. there is no transaction-oriented customer that becomes a relationship-oriented customer and vice versa.

\section{(ACP) Customer Portfolio}

The e-tailer has no customers in his portfolio before $t=0$. The customer portfolio $P F$ after the acquisition in $t=0$ consists of $N \in \mathbb{N}$ customers. The portfolio shares $r$ and $s$ of the segments $R$ and $S$ (with $r+s=1$ and $r \geq 0, s \geq 0$ ), given by the ratio of the number of customers in a segment and the total number $N$ of

6 The static model presented below is also applied in [29].

7 If the e-tailer wants to perform the optimization process once again at a later point in time, it follows that transaction-oriented customers have to be regained in order to make a repeated purchase. Obviously, the two defined segments are idealized in order to allow for a first simple analysis. 
customers in the portfolio, are the decision variables of the portfolio optimization in $t=0$ for the whole planning horizon until $t=T^{8}$.

For each customer segment $i$, with $i \in\{R ; S\}$, the average per capita cash flow $Q_{i}$ is given by

$$
Q_{R}=\left(\tilde{q}_{0, R}, \tilde{q}_{1, R}, \ldots, \tilde{q}_{T, R}\right) \text { and } Q_{S}=\left(\tilde{q}_{0, S}, 0, \ldots, 0\right)
$$

The components $\tilde{q}_{t, i}$ are the average net cash flows per customer in customer segment $i$ and represent the delta of cash in and outflows at time $t \in\{0, \ldots T\}$ :

$$
\tilde{q}_{t, i}=C F_{t, i}^{\text {in }}-C F_{t, i}^{\text {out }}
$$

$\widetilde{q}_{t, i}$ are independent and identically distributed random variables, which are given at the decision time $t=0$. The average per capita Customer Lifetime Value $C L V_{i}$ of segment $i$, which is also normalized to the number of customers in segment $i$ at $t=0$, is given by the expected NPV of $Q_{i}$ ( $z$ denotes the risk free market interest rate) ${ }^{9}$

$$
\mu_{i}=E\left(C L V_{i}\right)=\sum_{t=0}^{T} \frac{E\left(\tilde{q}_{t, i}\right)}{(1+z)^{t}}
$$

For the following model, we define the expected return per capita $\mu_{i}$ of customer segment $i$ as $E\left(C L V_{i}\right)$ at time $t=0$, as is done in equation (4). Hillier et al. [21] showed that if the net cash flows are supposed to be independent and identically distributed random variables, it may be concluded that the expected return per capita $\mu_{i}$ is asymptotically normally distributed. On the basis of assumptions $A C P$ and $A D M$, the expected NPV per capita of the customer portfolio $E\left(C L V_{P F}\right)$, shortly denoted as $\mu_{P F}$, may be calculated as the sum of the weighted NPV of both segments' $\mu_{i}$ :

$$
\mu_{P F}=E\left(C L V_{P F}\right)=r \cdot E\left(C L V_{R}\right)+s \cdot E\left(C L V_{S}\right)=r \cdot \mu_{R}+s \cdot \mu_{S}
$$

\section{(ACA) Customer Acquisition}

Customers can be acquired only at $t=0$. The customer segments are large enough and the e-tailer is comparably small enough so that there will never be a shortage of acquirable customers in a customer segment.

(ADM) Decision Maker

The risk-averse decision maker aims to maximize the utility per capita of the portfolio alternatives. The risk ${ }^{10}$ of the expected return per capita of customer

8 The planning horizon for the CLV calculation as well as for the optimization is assumed to be equal here. Of course, one may also model different planning horizons, however with the risk that the major cash inflows included in the CLV calculation may lie beyond the planning horizon for the optimization, leaving the decision maker potentially with an unintended result at the end of the planning horizon of the optimization.

9 A current survey of the market for CRM software according to Hippner et al. [22] shows that 58 of 78 CRM standard software products support the evaluation of customers. A study by Sackmann et al. [44] shows - at least for Germany - that monetary approaches of customer evaluation are increasingly applied. Thus, the necessary data may be already available in many companies.

${ }^{10}$ Risk includes both systematic risks (e.g. macroeconomic shocks, competitive environment) as well as unsystematic risks (e.g. product and pricing strategies of the e-tailer). 
segment $i$ is quantified by the standard deviation $\sigma_{i}=\sqrt{\operatorname{Var}\left(C L V_{i}\right)}$. The risk $\sigma_{P F}$ of the expected portfolio return per capita involves the standard deviation $\sigma_{i}$ of the portfolio segments as well as their covariance $\operatorname{Cov}_{R S}$, i.e. $\sigma_{P F}=\sqrt{r^{2} \sigma_{R}^{2}+s^{2} \sigma_{S}^{2}+2 r s \operatorname{Cov}_{R S}}=\sqrt{r^{2} \sigma_{R}^{2}+s^{2} \sigma_{S}^{2}+2 r \sigma_{R} s \sigma_{S} \rho_{R S}}$. The correlation coefficient $\rho_{R S}<1$ is given in time period $t=0$ and is constant over the planning horizon. For all possible values $\mathrm{x}$ assumed by the random variable $C L V_{P F}$, their utility is given by $u(x)=1-e^{-a x}$. The parameter $a$ denotes the Arrow-Pratt measure that indicates the individual level of risk aversion ${ }^{11}[1]$.

Schneeweiß showed that the only rational preference relation that meets assumption $\mathrm{ADM}$, i.e. in case of normally distributed random variables, the utility function given in (ADM) and compatibility with the Bernoulli-Principle, is given by the following equation [47]:

$$
\Phi_{u}\left(\mu_{P F}, \sigma_{P F}\right)=\mu_{P F}-\frac{a}{2} \sigma_{P F}^{2}=U_{P F} \rightarrow \max
$$

The parameters $\mu_{P F}$ and $\sigma_{P F}$ both depend on the portfolio shares $r$ and $s$ of the two customer segments, which have to be chosen so that $\Phi_{u}\left(\mu_{P F}, \sigma_{P F}\right)$ is maximized. In the context of relationship valuation, $a / 2$ is defined as a monetary factor that reflects the price per unit of risk, i.e. the reward asked by a risk-averse decision maker for carrying the risk $\sigma_{P F}$. Since the portfolio shares of the two customer segments sum up to one, the expected portfolio utility $U_{P F}$ is a monetary per capita amount.

\subsection{Portfolio Optimization - Static View}

For the optimization, firstly $\mu_{P F}$ and $\sigma_{P F}$ of all efficient portfolio alternatives have to be derived, i.e. the so-called efficient frontier (EF) is calculated, and secondly, the optimal portfolio based on the utility function provided in assumption (ADM) can be determined using equation (5).

Generally, the decision maker has to choose between portfolios with higher expected return accompanied by higher variance and portfolios with lower expected return and variance. Furthermore, he will only select a portfolio $P F$, which meets the following conditions and is therefore referred to as efficient [31]:

- The portfolio is a feasible portfolio, i.e. all portfolio weights are part of the feasible interval of $r, s \in[0 ; 1]$ and the portfolio shares sum up to one.

- If any feasible portfolio has a greater expected return, it must also have a greater variance of return than the portfolio $P F$.

- If any feasible portfolio has a smaller variance of return, it must also have a smaller expected return than the portfolio $P F$.

Analytically, this may be written as:

$$
\min _{r} \quad \sigma_{P F}^{2}=r^{2} \cdot \sigma_{R}^{2}+s^{2} \cdot \sigma_{S}^{2}+2 r s \rho_{R S} \sigma_{R} \sigma_{S}
$$

\footnotetext{
${ }^{11}$ For risk-averse decision maker: $a>0$; for risk-neutral decision maker $a=0$.
} 
The objective function (6) has to be minimized subject to the following constraints:

$$
\begin{gathered}
\bar{\mu}_{P F}=r \cdot \mu_{R}+s \cdot \mu_{S}(\text { see equation (4)) } \\
r \geq 0, s \geq 0(\text { see }(\mathrm{ACP})) \\
r+s=1(\text { see }(\mathrm{ACP}))
\end{gathered}
$$

Talking about the EF, one might think that with just two risky assets there may be four different cases to be differentiated, where relationship-oriented customers $(R)$ have a lower or higher return and at the same time a lower or higher risk compared to transaction-oriented customers (S). From portfolio selection theory, we know that the set of efficient portfolios, where for a given level of risk no other investment opportunity offers a higher return, form the EF. Generally, the EF in a no-short-sales setting corresponds to a concave curve ${ }^{12}$ in a risk-return diagram starting at the minimum-variance portfolio (MVP) and ending at the asset with the highest return (see bold line in the left hand side of Figure 1).

In the financial markets, higher risk is generally associated with a higher return. Obviously this need not be true if the "assets" are customers - an issue that deserves more thought in future research. However, even though the individual asset $R$ dominates asset $S$ ' (see left hand side of Figure 1), i.e. $R$ offers a higher return for less(!) risk, due to a sufficiently small correlation coefficient it can transpire that a mixture of these two assets is still superior in comparison to a full investment in asset $R$-depending on the risk preferences of the decision maker. In case the correlation coefficient is sufficiently high and the segment with the higher return carries sufficiently lower risk compared to the other segment, the EF is just the point R.

Remarkably, all possible mixtures of the two customer segments within the customer portfolio lie on the line that connects $R$ and $S$. Since the optimal portfolio has to be efficient, the point of tangency of the indifference curve (dotted line on the right hand side of Figure 1) and the EF, i.e. the point where the slopes of both functions are equal, represents the locus of the optimal portfolio at the given risk preference. Thus, after the EF has been determined, equation (5) may be used to determine the preferred customer portfolio weights. ${ }^{13}$

${ }^{12}$ In the special cases where $\rho_{R S}=1$ or $\rho_{R S}=-1$, the efficient frontier is a straight line.

${ }^{13}$ Finally, we may check if the utility per capita of the optimal portfolio covers the average NPV of direct and indirect fixed costs per capita. Buhl et al. [3] suggest a heuristic to account for these costs already within the optimization. 

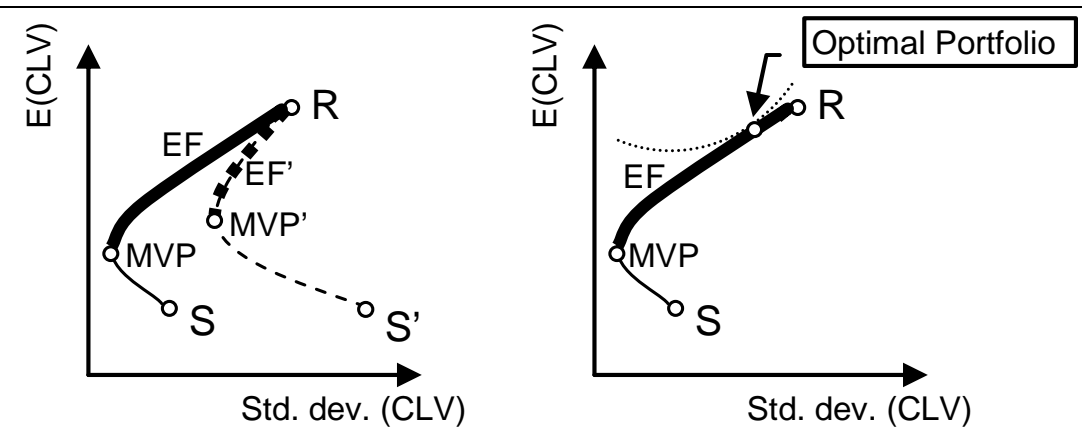

$\begin{array}{ll}E(C L V) & \text { Expected CLV of customer segment } \\ \text { Std. dev. } & \text { Standard deviation of CLV } \\ R & \text { Relationship-oriented customer segment } \\ S & \text { Transaction-oriented customer segment } \\ \text { MVP } & \text { Minimum-variance portfolio } \\ \text { EF } & \text { Efficient frontier }\end{array}$

Fig. 1. Efficient Frontier with two customer segments

The knowledge of the preferred customer portfolio weights allows an e-tailer to identify the deviation between the optimal customer portfolio from an integrated riskreturn perspective and the customer portfolio at the status quo. It should be noted that in the context of customer portfolios, it is generally not possible to adopt the portfolio by "selling" some shares of one segment in order to "buy" some of the other segment like in financial markets (see section 3.1). However, the result from the analysis is rather a hint as to where the focus of prospective acquisition efforts should lie: The customer segment where a shortage was identified, consequently leading to a (relative) increase in the portfolio weight of this segment.

With these first results, some limitations of the presented model should be noted. Obviously this is a simple model with just two segments and a one period optimization. Even though current data warehousing and data mining techniques are already very powerful, the parameter estimation, particularly with regard to the correlation coefficient, is a challenge. The segments are defined as idealized representations of customers in real life and it is assumed that with targeted marketing efforts it is possible to acquire the "right" customers. This may have become easier for e-tailers compared to traditional retail outlets, since much more computing power as well as data about (potential) customers are available and can be processed. ${ }^{14}$ In addition, individualization and personalization is achievable at acceptable costs on the Internet. Nevertheless, there is still a long way to go until such targeted and successful marketing campaigns are in place. Considering all the limitations mentioned above, results of the analysis have to be handled with care. Besides these limitations, Markowitz's Portfolio Selection Theory still gets by with much less restrictive assumptions compared to CAPM proposed in many other contributions (see above).

Moreover, there is another limitation that has to be taken into account. An additional way to optimally manage the customer portfolio is given by taking up

${ }^{14}$ See [34] for a discussion about the potential resources and the value of having complete information about a customer for CRM purposes. 
initiatives to work on the parameters themselves. This constitutes a major difference between financial markets and the "market of customers": While the return and volatility estimations of stocks, bonds and other financial assets are an exogenous input to the Markowitz model, CLV and its standard deviation are by far from being given. ${ }^{15}$ In contrast, these are the parameters companies are trying hard every day to improve. A huge body of literature specifically deals with measures to increase CLV and to lower the risk of churning. Suggested measures include:

- Introduction of loyalty programs or customer clubs, often associated with customer cards (an example are frequent flyer programs of all major airlines),

- Service-related measures: E.g. professional complaint management or preferred service for existing customers,

- Price-related measures: E.g. discounts or kick-back payments,

- Product-related measures: E.g. using data mining techniques to determine the next product to buy [26],

- Communication-related measures: E.g. apologies, explanations, additional information, arguments of benefits [48].

Particularly for e-tailers, the Internet offers possibilities to combine these more traditional marketing instruments (product, price, place, and promotion) with precision, payment, personalization, and push and pull [7].

\subsection{First Evaluation with an e-Tailer's Data Set}

For a better clarification of the model, the analysis of an optimal customer portfolio will be performed by using a publicly available, exemplary data set from the online retailer $\mathrm{CDNow}^{16}$. The data set contains 2357 customers, who made their first purchases at the CDNow-website in the first quarter of 1997 and were observed over a period of 39 weeks. For further details of the data set see [13], [14]. The sold goods are CDs and the relationship between customers and retailer is non-contractual. In total, 1411 customers bought only once and 946 up to 30 times.

The Pareto/NBD-Model is applied as method for segmenting the overall customer portfolio into the segments of relationship- and transaction-oriented customers. Subsequently, the customer segments are evaluated based on the segments' CLVs and their respective standard deviations before the EF is determined.

\section{Segmentation of the overall customer portfolio}

The first step in optimizing a customer portfolio from a risk management perspective is to differentiate between relationship- and transaction-oriented customer groups. In doing this for the CDNow data set, the Pareto/NBD-Model from [45] - particularly

15 This issue has been already discussed by [6], [9]. (Devinney et al. [10] call this issue with respect to product portfolio managerial control. Investors seldom have control over risk/return characteristics of an investment, while this is generally not true for risk/return characteristics of products.

${ }^{16}$ The data set is available at http://brucehardie.com/notes/004/. 
suitable for the analysis of situations with non-contractual customer relationships may be used, since it includes, among others, the transaction frequency. The model generates a probability $P$ (alive) $\in[0,1]$ per customer revealing whether a customer is still active or not. After calculating $P$ (alive) for every customer, a cutoff value $c$ has to be defined that separates according to their activity relationship- from transactionoriented customers. Due to a sharp kink of the curve of the $P$ (alive)-values, $c$ is set to 0.21 as the value to divide the two customer segments (see Table 1). ${ }^{17}$ The customers with $P$ (alive) higher $c$ represent the relationship-oriented segment $R$ and those with a lower $P$ (alive)-value - who bought only once or after several times in the beginning nothing more for the rest of the observation period - the transaction-oriented segment $S$.

\section{Valuating the different customer segments}

The base for the average per capita Customer Lifetime Value $C L V_{i}$ of segment $i$ are the individual CLVs of the customers. To calculate these and to get the NPV, it is necessary to know the exact purchasing dates so that the values can be discounted to $t_{0}$. Unfortunately, this information is not included in the data set of CDNow, so the needed purchasing dates are modeled by using random numbers following an equal distribution. An average cash flow per purchase has also been defined and was normalized to 1 . This enables a simple calculation of the CLVs by summing up the number of purchases per quarter and discounting these to $t_{0}$ with an assumed risk-free interest rate $z$ of $1 \%$ per quarter. To operate the portfolio optimization, simply an average CLV for each consumer segment is needed together with the standard deviation. The results for the CDNow data set are shown in Table 1. Apparently, at least for this data set, a higher return goes hand in hand with a higher risk.

Table 1. Characteristics of CDNow customer segments $R$ and $S$.

\begin{tabular}{|l|c|c|c|}
\hline & $\begin{array}{c}\text { Number of } \\
\text { customers }\end{array}$ & Average $C L V_{i}$ & $\begin{array}{c}\text { Standard } \\
\text { deviation of } C L V_{i}\end{array}$ \\
\hline $\begin{array}{l}\text { Segment } R \text { (relationship- } \\
\text { oriented customers) }\end{array}$ & $\begin{array}{c}698 \\
(30 \%)\end{array}$ & 3.8 & 2.8 \\
\hline $\begin{array}{l}\text { Segment } S \text { (transaction- } \\
\text { oriented customers) }\end{array}$ & $\begin{array}{c}1659 \\
(70 \%)\end{array}$ & 1.3 & 1.1 \\
\hline
\end{tabular}

\section{Calculating the efficient frontier and determining CDNow's customer portfolio}

Figure 2 shows alternative EF for three assumed correlation coefficients for the two identified segments, namely $p=0$ (assuming stochastic independence), $p=0.5$ (assuming a positive correlation), $p=1$ (assuming a perfect positive correlation). As expected, the higher the risk diversification potential is, the smaller the correlation of the expected CLV distribution of these two segments is.

Assuming independence of the CLV-development of the two segments $(p=0)$, the minimum variance portfolio (MVP) is characterized by a CLV of 1.6 and a respective

${ }^{17}$ Using a value of 0.5 does not change the general results of the following evaluation. For a more detailed discussion about the calculation see [29]. 
standard deviation of 1.0 . In this MVP, $86 \%$ of the customers are transaction-oriented and $14 \%$ are relationship-oriented. Thus, even extremely risk-averse decision makers would choose a portfolio consisting of shares of both segments instead of just addressing transaction-oriented customers.

The current situation for the data set of CDNow is depicted by the triangles in Figure 2. The expected CLV per capita of the portfolio is 2.0. If the portfolio construction was a deliberately managed process at CDNow this would imply a quite risk-averse management. Otherwise, the result may suggest that CDNow rethinks their customer acquisition and retention strategy in the future; given similar customer behavior.

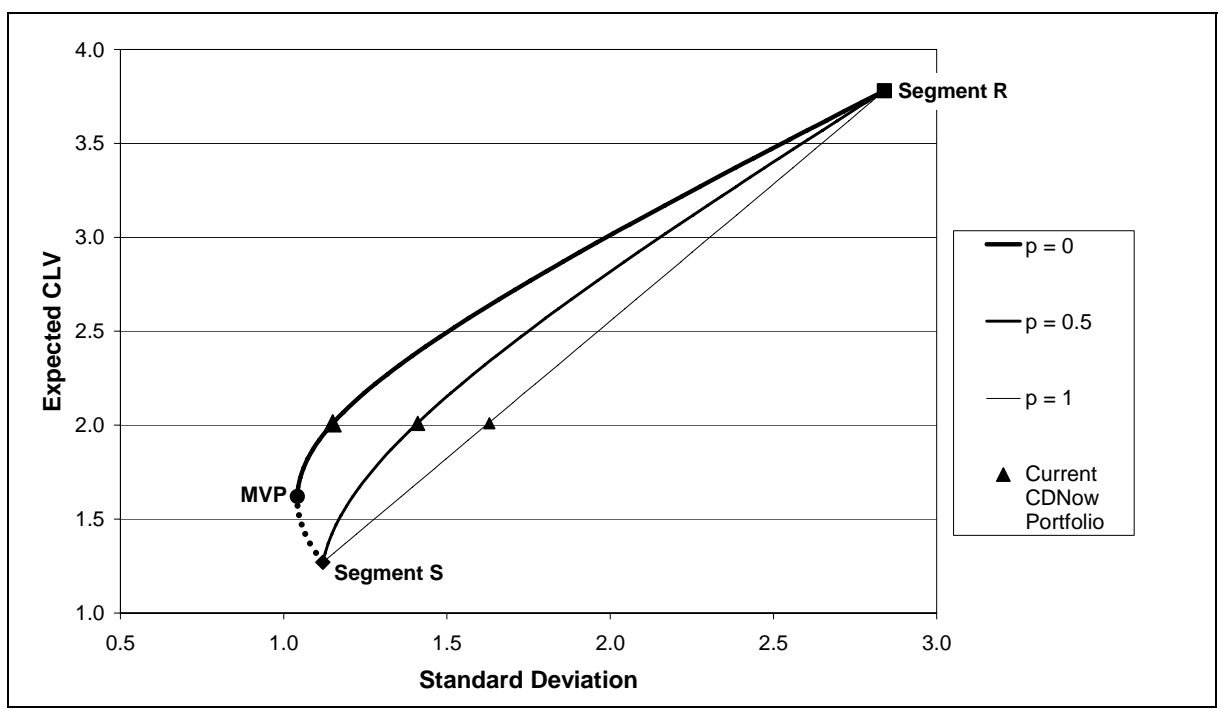

Fig. 2. Alternative efficient frontiers for CDNow Data set

\subsection{Portfolio Optimization - Dynamic View}

Of course, a one period optimization is not appropriate for businesses that permanently want to operate in a specific market. Also, the market environment might change leading to changing parameter estimations, which should also be reflected in the optimization process over time. One simple extension of the presented model is the application of the model after each period. This changes the optimization process a little bit, since by definition relationship-oriented customers stay with the e-tailer for several periods. These loyal customers do not have to be acquired again in the next period. Hence, their expected CLV will change due to the acquisition costs being regarded as sunk costs.

Moreover, there are at least two more reasons why CLV calculation for these customers has to be adapted. Firstly, the estimations may be adapted to the actual behavior in the first observed period. With this data, it should generally be possible to 
reach more accurate estimations. Secondly, if the CLV calculation is not primarily based on the expected termination of the relationship but - as can be observed in practice quite often - just on the near and midterm future cash flows (e.g. one to four years), the CLV estimations will tend to go up - if the relationship is appropriately managed - with increasing overall relationship duration (e.g. [36], see Figure 3).

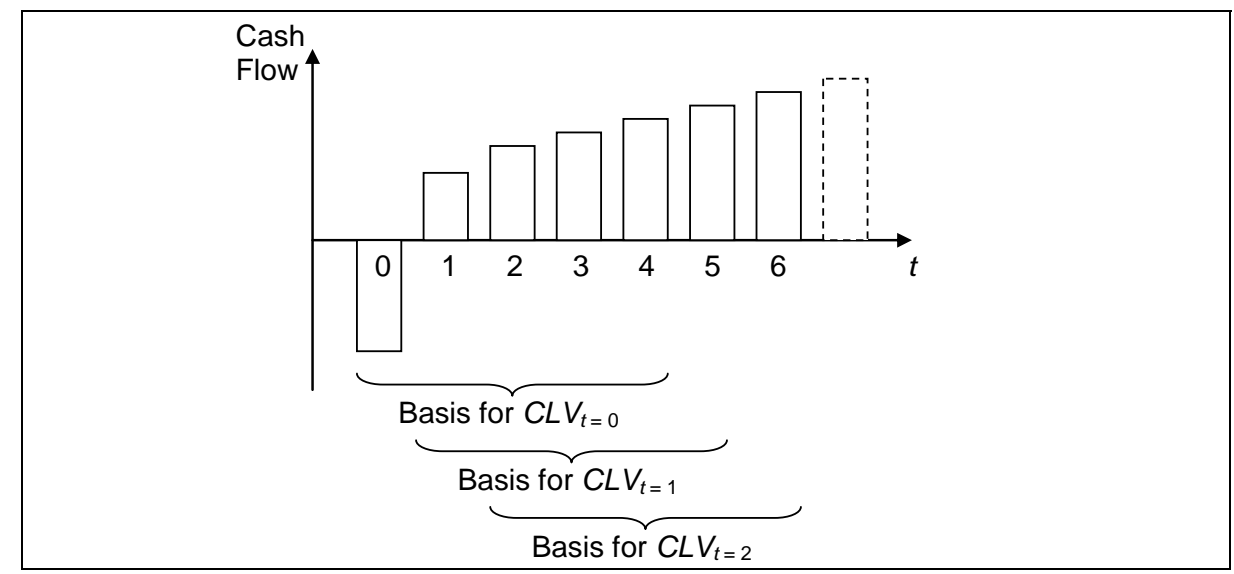

Fig. 3. Periodical CLV calculation for relationship-oriented customer (segment)

However, not only the parameter estimations have to be altered in this optimization process over time. Obviously, existing relationship-oriented customers are not a decision variable since it is not the question of whether they should be acquired or not. They are existing customers providing for future cash flows which are (still) risky and which will deviate from cash flow estimations for customers that shall be acquired (see above). Hence, these customers shall not be "fired" but contribute to the overall return and risk position of the e-tailer. Thus these customers form another constraint in the optimization process. Analytically, equations (6 - 9) change to

$$
\begin{gathered}
\min _{r_{\text {new }}} \sigma_{P F}^{2}=\sum_{k} k \cdot \sigma_{k}^{2}+\sum_{k} \sum_{l \neq k} k l \rho_{k l} \sigma_{k} \sigma_{l} \text { with } k, l \in\left\{r_{\text {new }}, s, r_{\text {exist }}\right\} \\
\mu_{P F}=r_{\text {new }} \cdot \mu_{R_{\text {new }}}+s \cdot \mu_{S}+r_{\text {exist }} \cdot \mu_{R_{\text {exist }}} \\
r_{\text {new }} \geq 0, s \geq 0\left(\mathrm{r}_{\text {exist }}=\text { const. from optimization in previous period }\right) \\
r_{\text {new }}+s+r_{\text {exist }}=1
\end{gathered}
$$

This situation is depicted in Figure 4. Each period, the existing customers tend to move to the upper left in the risk-return diagram (illustrated by the dotted arrow in the diagram to the right). The parameters for already acquired segments of relationshiporiented in each period can be determined prior to a new optimization process. Since these parameters are an exogenously given input to the optimization model, for reasons of clarity, they may also be merged to form just one segment of existing relationship-oriented customers as a constraint for the optimization. At the same time, the MVP will also move up and to the left in each period and thus the EF and also the optimal portfolio possibly changes from period to period. 


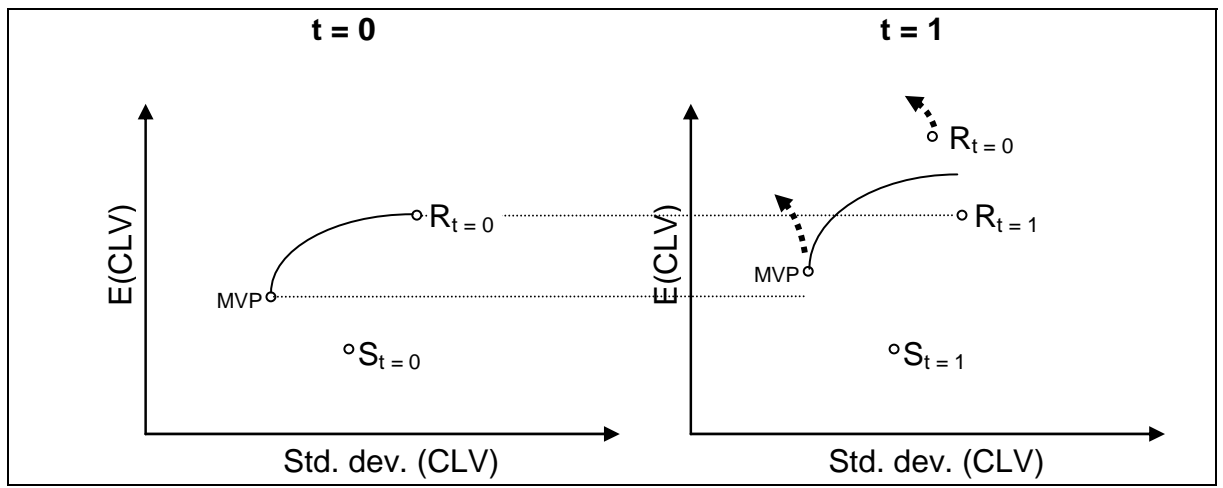

Fig. 4. Optimization over time

So what can we learn from this dynamic view? Firstly, relationship-oriented customers $(R)$ already in the customer base of an e-tailer form a new constraint that has to be determined and considered in each period. Secondly, the segment of already existing relationship-oriented customers $(R)$ tends to drift upwards and to the left also shifting the MVP. Thus, the EF also tends to drift upwards in each period. Consequently, a higher utility level may be realized. This does not seem surprising, since new customers are acquired after each period while relationship-oriented customers from previous periods stay with the e-tailer (see assumption AC). Hence, the e-tailer is growing. However, if management is at least slightly risk averse, sooner or later a state of saturation is reached: If the portfolio of existing (relationshiporiented) customers is comparably large in relation to the amount of money that may be invested to acquire a small number of new customers, it may become perfectly rational to focus just on transaction-oriented customers in order to realize risk diversification effects. ${ }^{18}$ The higher the risk aversion of management, the sooner such a "steady state" will be reached.

Customer portfolio management is an ongoing process. Acquisition efforts and measures to increase customer loyalty have to be adapted and adjusted in each period. Still one has to be aware that we perform a sequential set of one-period-optimizations, always taking the results of the optimization of the previous period into account. There is no guarantee that following this sequential approach leads ex post to an overall maximum. Nevertheless, the extended version of the basic model is a first step in the direction to more realistic assumptions.

\section{Conclusion and Outlook}

After years of proposing a focus on turning customers into loyal customers, it seems that in the last couple of years a more differentiated view has made its way in

18 It is assumed though that the correlation between newly acquired and already existing relationship-oriented customers equals 1. 
literature as well as in practice. Moreover, recent studies suggest that disloyal, transaction-oriented customers who do not expect and ask for bonus programs or other forms of customer loyalty measures may still constitute a quite profitable customer segment in the overall customer portfolio of an e-tailer. Acknowledging these issues, new questions arise - if management is considered as being risk-averse concerning the appropriate mix of two or more customer segments with different buying behavior. Traditional customer evaluation methods mostly focus on evaluating customers one by one. Including risk into this consideration most often comes as a mere premium on the risk free discount rate for the CLV calculation. We propose a different approach in this contribution.

With regard to customers as assets, we transfer and apply Portfolio Selection Theory due to Markowitz [31], to the issue of customer portfolio optimization. With our novel model, it is possible to account for different buying behavior of two (or potentially more) customer segments while having an integrated view on return (CLV) and risk (here measured as the standard deviation of the CLV within a customer segment). In a quite simple analysis, just looking at relationship-oriented and transaction-oriented customers, it turns out that an optimal mix of these two customer segments within a customer portfolio will typically include shares of both segments. Hence, focusing just on (potentially) loyal customers may be optimal with respect to the expected CLV, but not necessarily with respect to the overall expected utility of a customer portfolio, incorporating the risk of future cash flows. Moreover, we showed the applicability of our model using a publicly available data set of the e-tailer CDNow and provided for a first extension to get a more dynamic view into the process of customer portfolio optimization. The results of the extended analysis showed that a point of saturation may be reached leading to the situation that from this period onwards just transaction-oriented customers are targeted in the acquisition efforts.

The results of the analysis contribute to the understanding of customer portfolio management and optimization. It may facilitate a decision maker concerning the allocation of marketing budget for customer acquisition. Marketing measures particularly when talking about e-tailers operating primarily on the Internet - may be designed to address specific customers segments. Still the results above have to be carefully applied. Obviously, there will be market circumstances where an unlimited number of customers in each defined segment cannot be assumed and an ex ante segmentation just based on some limited data will (often) be associated with risk.

Nevertheless, customer portfolio optimization and management are interesting and demanding issues not only in research. A current study among German corporations reveals that there is substantial demand for quantitative approaches in customer portfolio management within the companies' CRM-activities [44]. However, a mere quarter of the respondents in that survey already have quantitative customer evaluation methods, such as the CLV, in place. So the basis for the application of the approach suggested above is still comparably small - but growing.

There are a lot of open research questions in these areas. Based on this contribution, we identified four major topics for future steps. First, an empirical investigation with an e-tailer going beyond the limited data set of CDNow is envisaged. Second, the presented model should be expanded to incorporate an arbitrary number of segments and issues like that of the customer retention rate should 
be included. Third, the issue of managing customer relationships in order to increase the expected CLV and decrease the risk of churning on the one hand has to be formally combined with a simultaneous optimization of the overall customer portfolio. Fourth, the dynamic character of customer portfolio management as an ongoing process should be incorporated in the model beyond the first step discussed in this contribution.

\section{Acknowledgements}

The authors wish to thank two anonymous reviewers for their assistance and also the participants of the INFORMS International Puerto Rico 2007 Meeting and the FinanceCom 2007 Workshop in Montreal. Finally, the authors extend their thanks the Bundesministerium für Bildung und Forschung (Federal Ministry of Education and Research) for the financial support during the EVENT project as part of the "Internetökonomie" research program.

\section{References}

1. Bamberg, G., Coenenberg, A.: Betriebswirtschaftliche Entscheidungslehre. $12^{\text {th }}$ edition, Vahlen, Munich (2004)

2. Bitran, G., Mondschein, S.: A Comparative Analysis of Decision Making Procedures in the Catalog Sales Industry. In: European Management Journal 15, 105-116 (1997)

3. Buhl, H.U., Heinrich, B., Singbartl, A.: Customer Portfolio Management in the Financial Services Industry. Discussion Paper, University of Augsburg, Augsburg (2005)

4. Campbell, N.C.G., Cunningham, M.T.: Customer analysis for strategy development in industrial markets. In: Strategic Management Journal 4, 369-380 (1983)

5. Cardozo, R.N., Smith, D.K.: Applying Financial Portfolio Theory to Product Portfolio Decisions: An Empirical Study. In: Journal of Marketing 47, 110-119 (1983)

6. Cardozo, R.N., Smith, D.K.: On the Use of Financial Portfolio Theory in Marketing Decisions: A Reply to Devinney, Stewart, and Shocker. In: Journal of Marketing 49, 113$115(1985)$

7. Chen, C.Y.: The comparison of structure differences between internet marketing and traditional marketing. In: International Journal of Management and Enterprise 3, 397-417 (2006)

8. Copeland, T., Weston, J., Shastri, K.: Financial Theory and Corporate Policy. $4^{\text {th }}$ edition, Pearson Addison Wesley, Boston (2005)

9. Devinney, T.M., Stewart, D.W., Shocker, A.D.: A Note on the Application of Portfolio Theory: A Comment on Cardozo and Smith. In: Journal of Marketing 49, 107-112 (1985)

10.Devinney, T.M., Stewart, D.W.: Rethinking the Product Portfolio: A Generalized Investment Model. In: Management Science 34, 1080-1095 (1988)

11.Dhar, R., Glazer, R.: Hedging Customers. In: Harvard Business Review 81, 86-92 (2003)

12.Dowling, G.R., Uncles, M.: Do Customer Loyalty Programs Really Work?. In: Sloan Management Review 38, 71-82 (1997)

13.Fader, P.S., Hardie, B.G.S.: Forecasting Repeat Sales at CDNOW: A Case Study. In: Interfaces 31, 94-107 (2001)

14.Fader, P.S., Hardie, B.G.S., Lee, K.L.: Counting Your Customers the Easy Way: An Alternative to the Pareto/NBD Model. In: Marketing Science 24, 275-284 (2005) 
15.Ford, D., Gadder, L.-E., Hakansson, H., Snehota, I.: Managing Business Relationships. $2^{\text {nd }}$ edition, John Wiley \& Sons, West Sussex (2003)

16.Ganesan, S.: Determinants of Long-Term Orientation in Buyer-Seller Relationships. In: Journal of Marketing 58, 1-19 (1994)

17.Garbarino, E., Johnson, M.S.: The Different Roles of Satisfaction, Trust, and Commitment in Customer Relations. In: Journal of Marketing 63, 70-78 (1999)

18.Goldsmith, D.: Transactions Costs and the Theory of Portfolio Selection. In: Journal of Finance 31, 1127-1139 (1976)

19.Gupta, S., Lehmann, D.: Customers as Assets. In: Journal of Interactive Marekting 17, 9-24 (2003)

20.Gupta, S., Lehmann, D., Stuart, J.: Valuing Customers. In: Journal of Marketing Research 41, 7-18 (2004)

21.Hillier, F.S., Heebink, D.V.: Evaluating Risky Capital Investments. In: California Management Review 8, 71-80 (1965)

22.Hippner, H., Hoffmann, O., Wilde, K.D.: CRM Studie 2007. Katholische Universität Eichstätt-Ingolstadt (2007)

23.Hogan, J., Lehmann, D., Merino, M., Srivastava, R., Thomas, J., Verhoef, P.: Linking Customer Assets to Financial Performance. In: Journal of Service Research 5, 26-38 (2002)

24.Hogan, J., Lemon, K., Libai, B.: What is the True Value of a Lost Customer?. In: Journal of Service Research 5, 196-208 (2003)

25.Hopkinson, G., Lum, C.Y.: Valuing customer relationships: Using the capital asset pricing model (CAPM) to corporate relationship risk. In: Journal of Targeting, Measurement and Analysis for Marketing 10, 220-232 (2002)

26.Knott, A., Hayes, A., Neslin, S.: Next-product-to-buy models for cross-selling applications. In: Journal of Interactive Marketing 16, 59-75 (2002)

27.Kotler, P., Levy, S.: Demarketing, Yes, Demarketing. In: Harvard Business Review 49, 74 80 (1971)

28.Kumar, V., Ramani, G., Bohling, T.: Customer Lifetime Approaches and Best Practice Applications. In: Journal of Interactive Marketing 18, 60-72 (2004)

29.Kundisch, D., Sackmann, S., Ruch, M.: CRM and Customer Portfolio Management for ETailers. In Proceedings of the Forty-First Annual Hawaii International Conference on System Sciences (HICSS-41), IEEE Computer Society Press, Los Alamitos, (2008)

30.Lumby, S., Jones, C.: Investment appraisal and financial decisions. Thomson Learning, London, England (2001)

31.Markowitz, H.: Portfolio Selection: Efficient Diversification of Investments. John Wiley \& Sons, New York (1959)

32.Markowitz, H.: Foundations of Portfolio Theory. In: Journal of Finance 46, 469-477 (1991)

33.Morgan, R.M., Hunt, S.D.: The Commitment-Trust Theory of Relationship Marketing. In: Journal of Marketing 58, 20-38 (1994)

34.Padmanabhan, B., Zheng, Z., Kimbrough, S.: An Empirical Analysis of the Value of Complete Information for eCRM Models. In: MIS Quarterly 30, 247-267 (2006)

35.Rappaport, A.: Creating Shareholder Value: A Guide for Managers and Investors. The Free Press, New York (1998)

36.Reichheld, F.F., Sasser, E.W.: Zero Defections: Quality Comes to Service. In: Harvard Business Review 68, 105-111 (1990)

37.Reichheld, F.F., Teal, T.: The Loyalty Effect. Harvard Business School Press, Boston (1996)

38.Reinartz, W.J., Kumar, V.: On the Profitability of Long-Life Customers in a Noncontractual Setting: An Empirical Investigation and Implications for Marketing. In: Journal of Marketing 64, 17-35 (2000)

39.Reinartz, W.J., Kumar, V.: The Mismanagement of Customer Loyalty. In: Harvard Business Review 80, 86-94 (2002) 
40.Rust, R., Lemon, K., and Narayandads, D.: Customer Equity Management. Prentice Hall, Englewood Cliffs (2005)

41.Ryals, L.: Are your customers worth more than money? In: Journal of Retailing and Consumer Services 9, 241-251 (2002)

42.Ryals, L.: Measuring risk and returns in the customer portfolio. In: Journal of Database Marketing 9, 219-227 (2001)

43.Ryals, L.: Making customers pay - measuring and managing customer risk and. returns," Journal of Strategic Marketing 11, 165-177 (2003)

44.Sackmann, S., Kundisch, D., Ruch, M.: CRM, Kundenbewertung und Risk-ReturnSteuerung im betrieblichen Einsatz. In: HMD - Praxis der Wirtschaftsinformatik 259, (2008)

45.Schmittlein, D.C., Morrison, D.G., Colombo R.: Counting your Customers: Who are they and what will they do next?. In: Management Science 33, 1-23 (1987)

46.Schmittlein, D.C., Peterson R.A.: Customer Base Analysis: An Industrial Purchase Process Application. In: Marketing Science 13, 41-67 (1994)

47.Schneeweiß, H.: Entscheidungskriterien bei Risiko. Springer, Heidelberg (1967)

48.Scullin, S.S., Fjermestad, J., Romano Jr., N.C.: E-relationship marketing: changes in traditional marketing as an outcome of electronic customer relationship management. In: Journal of Enterprise Information Management 17, 410-415 (2004)

49.Sheth, J.N., Parvatiyar, A.: Relationship in Consumer Markets: Antecedents and Consequences. In: Journal of the Academy of Marketing Science 23, 255-271 (1995)

50.Srivastava, R., Tasadduq, S., Fahey, L.: Driving Shareholder Value: The Role of Marketing in Reducing Vulnerability and Volatility of Cash Flows. In: Journal of Market Focused Management 2, 49-64 (1997)

51.Wedel, M., Kamakura, W.: Market Segmentation: Conceptual and Methodological Foundations. Kluwer, Dordrecht (2000)

52.Zeithaml, V.A., Rust, R.T., Lemon, K.N.: The Customer Pyramid: Creating and Serving Profitable Customers. In: California Management Review 43, 118-142 (2001) 